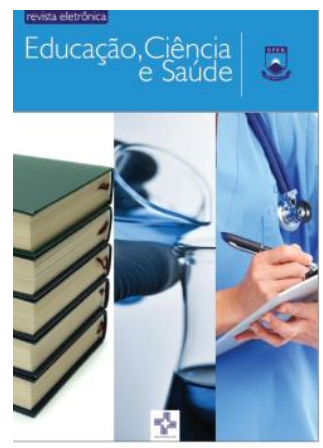

EDUCAÇÃO CIÊNCIA E SAÚDE

http://dx.doi.org/10.20438/ecs.v5i2.142

\title{
ABORDAGEM SOBRE O CERRADO EM UMA ESCOLA MUNICIPAL DE TERESINA-PI
}

\author{
Ana Raquel Lopes Nascimento ${ }^{1}$, Emerson Portela Sena ${ }^{1,2}$, Juliana Maria da \\ Silva Batista ${ }^{1}$, Ruth Raquel Soares de Farias ${ }^{3}$ \\ ${ }^{1}$ Curso de Licenciatura em Ciências Biológicas, Universidade Federal do Piauí, Teresina-PI, \\ Brasil. \\ ${ }^{2}$ Bolsista do Programa Institucional de Bolsas de Iniciação Científica. \\ ${ }^{3}$ Prof ${ }^{a}$ da Universidade Federal do Piauí, Teresina, PI, Brasil. \\ E-mail para correspondência:rakellllopes@gmail.com
}

\begin{abstract}
Resumo
O cerrado, por ser um bioma rico em biodiversidade, possui grande importância no âmbito ecológico, devido sua fauna e flora abundante, econômico, principalmente na exploração de recursos naturais, e também farmacêutico, devido seus potenciais terapêuticos. Porém, este bioma tem sofrido com a interferência humana que pode ocasionar o seu desaparecimento. Diante desse fato, fez-se necessário o desenvolvimento do seguinte trabalho, realizado através de palestras com aplicação de questionários constituídos de perguntas objetivas e fechadas, que visou aferir o nível de conhecimento dos alunos sobre o bioma cerrado, buscando alcançar uma mobilização através de ações educacionais que possam conscientizar e preservar esse bioma. Por meio deste trabalho foi possível perceber quais ideias e conhecimentos acerca do bioma, adquiridos principalmente em séries anteriores, os alunos traziam consigo, destacando a importância ecológica, social, ambiental e econômica deste rico ecossistema de transição. Dessa forma, o bioma cerrado vem passando por alterações que influenciam sua fauna e flora de forma negativa, necessitando de ações que possam trazer soluções cabíveis aos problemas a ele relacionados principalmente por meio de ações educativas.
\end{abstract}

Palavras-chave: preservar, alunos, conscientizar, ação educativa.

\begin{abstract}
Cerrado, being a biome rich in biodiversity, has great importance in the ecological scope, due to its abundant fauna and flora, economic, mainly in the exploration of natural resources, and also pharmaceutical, due to its therapeutic potentials. However, this biome has suffered with human interference that may lead to its disappearance. Faced by this situation, it was necessary the development of this search, carried out through lectures with application of questionnaires with objective and closed questions, aiming to gauge students' knowledge about the cerrado biome, willing to mobilize through educational actions to raise awareness and preserve this biome. Through this search, it was possible to identify which ideas and knowledge about biome, acquired mainly in previous series, the students have brought, emphasizing the ecological, social, environmental and economic importance of this rich ecosystem of transition. Therefore, the cerrado biome has
\end{abstract}


been having changes that influence its fauna and flora in a negative way, necessitating actions and solutions to problems through educational actions.

Keywords: preserving, students, awareness, educational action.

\section{Introdução}

O cerrado brasileiro ocupa uma área contínua de quase 2 milhões de $\mathrm{km}^{2}$ totalizando cerca de $24 \%$ das terras brasileiras, onde aproximadamente $35 \%$ das espécies presentes neste ambiente são endêmicas (MYERS et al., 2005; MENDONÇA et al., 2008; IBGE, 2012.). A área de abrangência desse domínio estende-se desde o estado do Amapá e Roraima, até o Paraná, já abaixo do trópico de capricórnio. Esse bioma também aparece desde o estado de Pernambuco, passando por Alagoas e Sergipe até o estado do Pará e Amazonas, sendo que neste Estado com "invaginações" para o interior da floresta amazônica. (EMBRAMPA, 2008.)

O cerrado está localizado em uma região de clima predominantemente tropical, em que é característico a presença de duas estações bem definidas, uma chuvosa que dura dos meses de outubro a abril, e outra seca, que vai desde o mês de maio até o mês de setembro. Predominam espécies vegetais do tipo tropófilas, que são plantas que se adaptam em determinadas estações distintas. Além disso, apresenta em sua maioria vegetação caducifólias, ou seja, perdem as suas folhas em uma determinada época do ano, troncos grossos e galhos retorcidos e com raízes profundas. (DREWS, Y. M., et al., 2015) *

Os métodos que visam à preservação do cerrado têm embasamento não só na elevada biodiversidade, característica do bioma, mas também pela forte pressão exercida pelo homem (MITTERMEIER., et al., 1998). A enorme expansão agropecuária no bioma teve início a partir da década de 70 devido à rápida alteração da fronteira agrícola. Dessa forma, os desmatamentos, queimadas, a correção do solo de caráter ácido e a utilização de fertilizantes químicos aumentaram consideravelmente, contribuindo para o surgimento de problemas ecológicos e ambientais no bioma. Atualmente as atividades agropecuárias e a ocupação urbana, de forma desordenada, são os impactos mais vistos no cerrado brasileiro. (CLIN \& MACHADO 2005.)

Consequentemente, a preservação ambiental tem sido uma das preocupações que mais se destaca nos diversos setores da sociedade. Nos últimos anos, a busca por incorporar conceitos e valores que estejam vinculados 
à conservação do meio ambiente através da educação é algo crescente e de destaque principalmente nos meios midiáticos, pois a aprendizagem não depende exclusivamente do próprio aprendente, ou somente da sua ação sobre o meio ou da sua estrutura mental, mas das contingências de reforço, pois, dadas as condições adequadas todos os seres aprendem. Uma vez que a aprendizagem é o resultado de um processo de modelagem que tem como base o comportamento operante que não necessita do controle de estímulos, pois o número de repostas condicionadas pelo organismo sem estimulo externo é mínimo. (SILVA, Cleânia d. S., AGUIAR, Olivette, R. B. P. 2010).

Por ser um fator de importância e influência social, a educação, é usada como ferramenta no processo de conscientização e preservação dos recursos naturais. Bezerra e Goulart (2012) afirmam que a educação é um processo importante na tentativa de mostrar aos alunos o valor, características específicas e atual estado de degradação deste bioma, pois pode auxiliá-los na constituição de uma visão crítica sobre as ações do ser humano. Com base nessa percepção realizou-se uma análise do nível de conhecimento dos alunos sobre o cerrado brasileiro, com o intuito de auxiliar a formação de uma consciência ecológica de preservação, o que raramente ocorre em escolas da educação básica.

\section{METODOLOGIA}

\subsection{A instituição educacional}

As atividades foram realizadas em uma escola da rede pública de ensino em Teresina, PI. O andamento do projeto deu-se após agendamento com a instituição. Para sua realização foram escolhidas duas turmas do $9^{\circ}$ ano do ensino fundamental. Esses alunos foram escolhidos pois estão terminando a segunda fase da educação básica e adentrando ao ensino médio. Desse modo, teoricamente, esses alunos já deveriam ter conhecimento sobre tal conteúdo tendo como base conhecimentos adquiridos, principalmente nas disciplinas de ciências e geografia,em que ambas abordam a temática ambiental ao longo da formação escolar dos alunos até a série final da educação de nível fundamental.

\subsection{Realização da pesquisa e coleta de dados}

$\mathrm{Na}$ escola foram realizadas palestras em dias alternados com a separação das turmas em duas etapas para realização do projeto. No início de cada palestra 
salientou-se os aspectos gerais da pesquisa e novamente informou os alunos que estavam livres para participar ou não da realização da atividade. A execução consistiu em três momentos: Um pré-teste: questionário aplicado no primeiro contato; palestra: com exposição do tema Cerrado Brasileiro que abrangeu as formas de conservação e importância ecológica, econômica e social, destacando os principais métodos de desmatamento e formas de disseminação e combate do fogo; em seguida, em um último contato com os alunos, um pós-teste: que consistiu da reaplicação do questionário inicial, acrescido de questionamentos sobre a relevância das informações abordadas durante a palestra. A respeito dos alunos, foram respondidos, ao todo, 69 questionários, sendo 38 da turma A e 31 da turma B. Dessa forma, ocorreu um encontro com cada turma de alunos e estes tiveram uma duração média de 120 minutos.

Após reaplicação do teste foi aberto um momento para discussões entre os alunos, sobre o tema abordado na discussão, com exibição de um vídeo explicativo generalizado, sobre os principais temas abordados durante a atividade.

Os questionários para avaliação do conhecimento dos alunos foram elaborados com base nos conteúdos estabelecidos nos Parâmetros Curriculares Nacionais (PCN) para as séries do ensino básico do nível fundamental, no ensino de ciências e geografia

Tanto o questionário pré-teste como pós-teste consistiram de cinco e oito perguntas fechadas, respectivamente, de cunho objetivo sem necessidade de identificação do aluno, apenas da instituição e série. Após a realização das atividades com os alunos, os dados obtidos foram quantificados, e os resultados estáticos calculados foram expressos em forma de gráficos.

\section{$3 \quad$ Resultados e Discussões}

Os livros didáticos são utilizados como principal fonte de informação na educação brasileira, por alunos e professores (BEZERRA e SUESS, 2013), uma vez que os mesmos são constantes no meio educacional, partindo da educação de nível básico até o nível superior, servindo como recurso de apoio na prática pedagógica.

Apesar de a escola ser considerada como local social da educação, não é o único espaço para se aprender, apenas faz parte de um conjunto social no qual 
interagimos cotidianamente com os mais diversos tipos de saberes. A mídia é atualmente a maior fonte de informação e entretenimento que a população possui, porém, os meios de comunicação são agentes produtores de acontecimentos e não de consciência, mas que influenciam a quantidade de informações atreladas às contingências de reforço.

Apesar de os alunos já terem estudado sobre bioma Cerrado, em primeiro momento ao serem questionados sobre o que é Cerrado e as principais características da flora, uma característica que se mostrou muito presente foi a visão significativa deste bioma, elencando-o basicamente a características como sendo uma formação ecológica brasileira, que segundo Ribeiro e Walter (2008), se caracteriza pela presença de árvores de pequeno porte, inclinadas, tortuosas, com ramificações irregulares e geralmente com incidência de queimadas. Os troncos das espécies lenhosas possuem casca espessa, as folhas são rígidas e coriáceas, gemas apicais protegidas por densa pilosidade, ou seja, várias características que apontam para a adaptação ao clima seco. Conforme expresso no gráfico 1 da seção 3.1 .

Com relação aos conhecimentos sobre espécies da fauna do cerrado, a quantificação em porcentagem, foi significativa, atingindo em média $86 \%$ de acertos conforme gráfico 1. O conhecimento sobre a biodiversidade também está relacionado aos conteúdos de livros didáticos, que mostram principalmente figuras de mamíferos e aves. Analisando os trabalhos de Bizerril (2001) e Bezerra e Suess (2013), que pesquisaram a abordagem do Cerrado em livros didáticos, observam que os animais que mais aparecem são: o lobo-guará, ema, tamanduá-bandeira, seriema, veado campeiro e tatu, resultados que se assemelham às respostas dos alunos, tanto nos questionários de pré e pósteste.

$\mathrm{Na}$ análise percebeu-se de forma clara a capacidade de influência midiática, pautada nas respostas dos alunos, em que os animais citados, embora os nomes não sejam específicos, rementem a espécies ameaçadas de extinção, frequentemente mencionadas em meios midiáticos quando são divulgadas algumas informações relacionadas ao bioma Cerrado, ou seja, isso mostra que os conhecimentos dos alunos podem ser realmente influenciados por meios midiáticos. 
$\mathrm{Na}$ quarta questão indagou-se sobre o clima típico do cerrado caracterizado por apresentar duas estações bem definidas, sendo um período chuvoso no verão e um período de seca durante o inverno. A análise das respostas obtidas pelos testes mostrou-se satisfatória, visto que tais características são marcantes desse bioma, portanto de fácil identificação conforme indicam os dados do gráfico 1.

Sabe-se que o fogo é uma característica natural do bioma, sendo registrado há milhares de anos (COUTINHO, 1980). O fogo originado por fatores naturais pode ser benéfico para o bioma, pois contribui para a germinação de sementes, que necessitam de um choque térmico para que seja efetuada a quebra de sua dormência vegetativa, principalmente as que são impermeáveis. A rápida elevação da temperatura causa fissuras na semente, favorecendo a penetração de água e iniciando o processo de germinação. As queimadas contribuem também para a ciclagem de nutrientes do solo. Entretanto percebeu-se que em relação a importância do fogo para o cerrado os alunos apresentam dificuldade em compreender a importância biologia desse fator para o ecossistema, principalmente ao assimilar com as práticas cotidianas à ação do fogo, como por exemplo, as queimadas, auxiliando na preparação da terra para o plantio, bem como o desmatamento de grandes áreas facilitando o acesso de máquinas.

\subsection{Análises quantitativas}

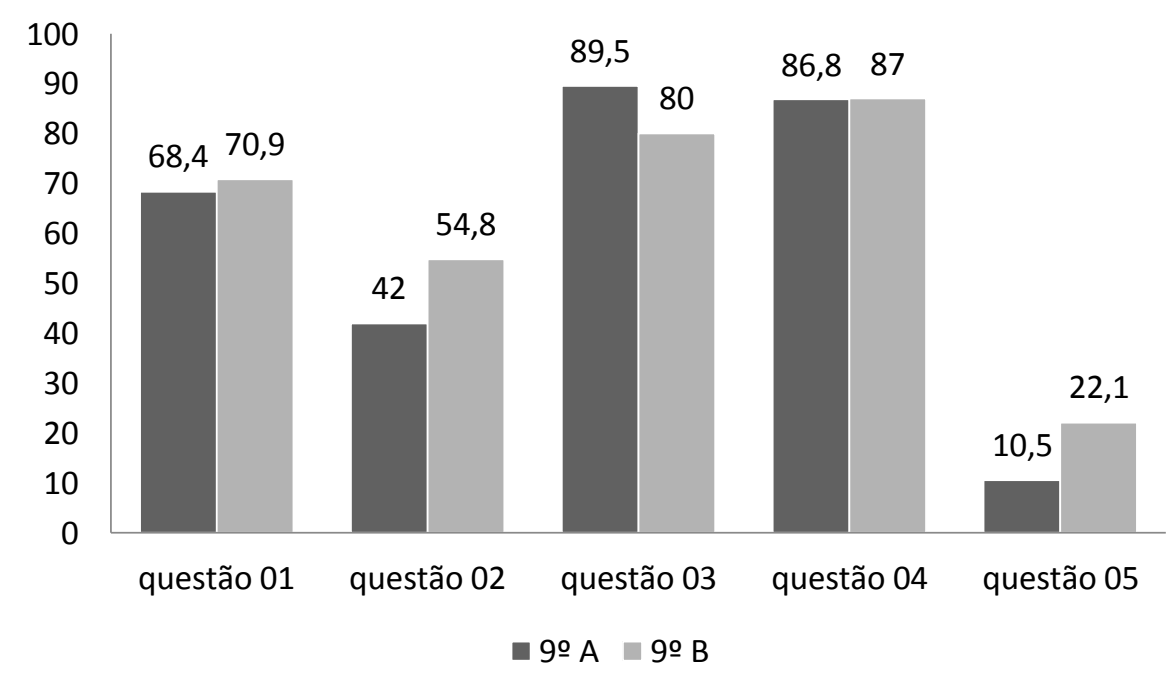

Gráfico 1. Porcentagem de acertos das questões do pré- teste nas duas turmas.

Fonte: Dados da Pesquisa, 2017. 
Com base nos dados do gráfico é possível perceber o conhecimento dos alunos acerca do que é cerrado, questão 01, é satisfatória em ambas as turmas. As características da flora, questão 02, encontra-se em um nível razoável para a turma A e mediano para a turma B. Já as questões 03 e 04, que abordam sobre fauna e clima, respectivamente, apresentam-se em nível satisfatório para as duas turmas. No que se refere a questão 05 , sobre a importância do fogo para o cerrado, é notável o baixo nível de conhecimento dos alunos sobre esse fator. Salientando-se que essa amostragem foi feita antes da palestra.

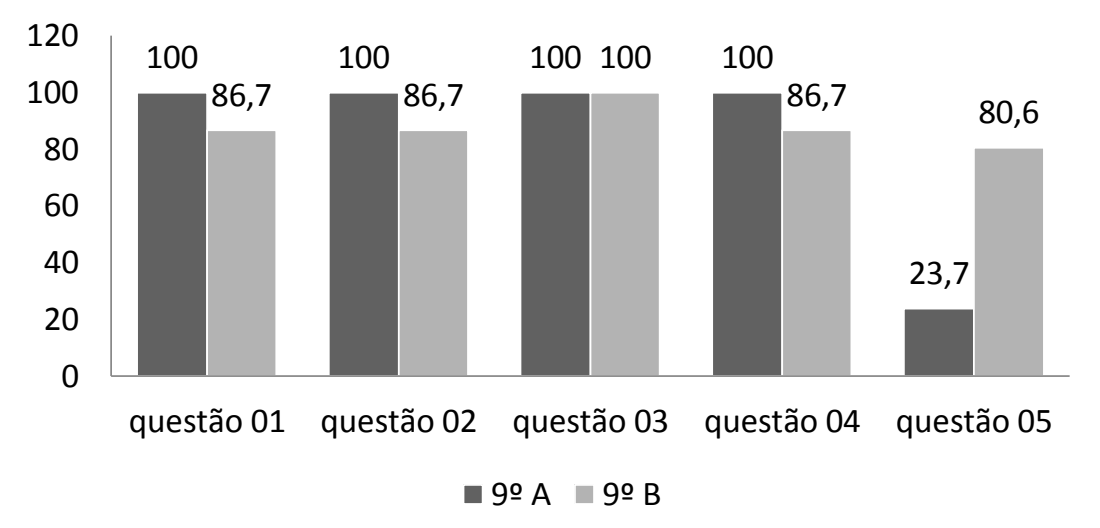

Gráfico 2. Porcentagem de acertos das questões do pós-teste com as duas turmas.

Fonte: Dados da Pesquisa, 2017.

É possível perceber que houve aumento significativo no número de acertos relacionados às questões $01 \mathrm{a}$ 04, em ambas as turmas. Porém mesmo após abordagem sobre cerrado, notou-se desempenho diferenciado nas duas turmas com relação a temática "importância do fogo para o cerrado" na questão 05, em que a maioria associa tal fenômeno às práticas cotidianas de cultivo do solo.

\subsection{Quantificação de conhecimento Pós-Palestra}




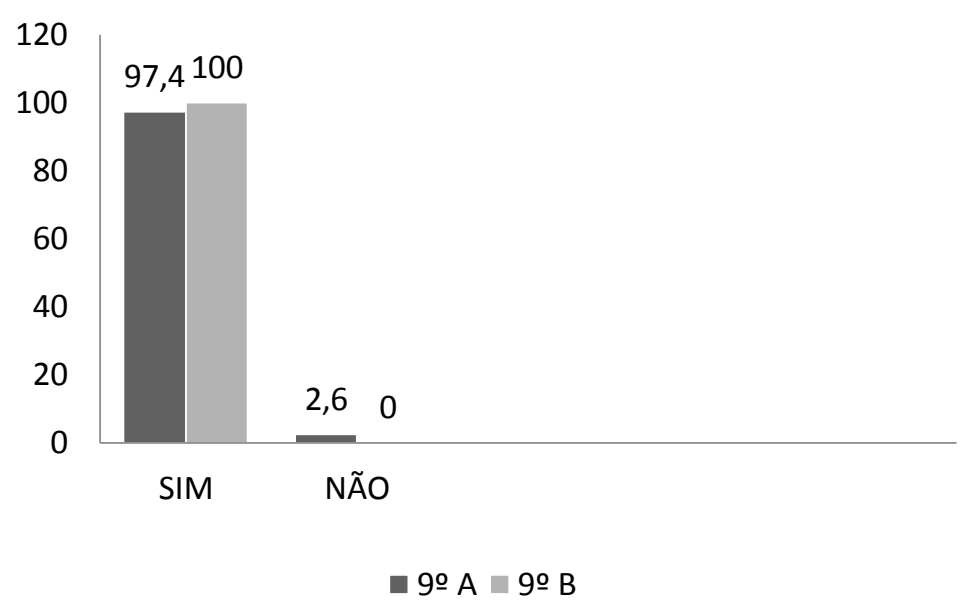

Gráfico 3. Porcentagem de novas abordagens sobre cerrado. (questão 06) Fonte: Dados da Pesquisa, 2017.

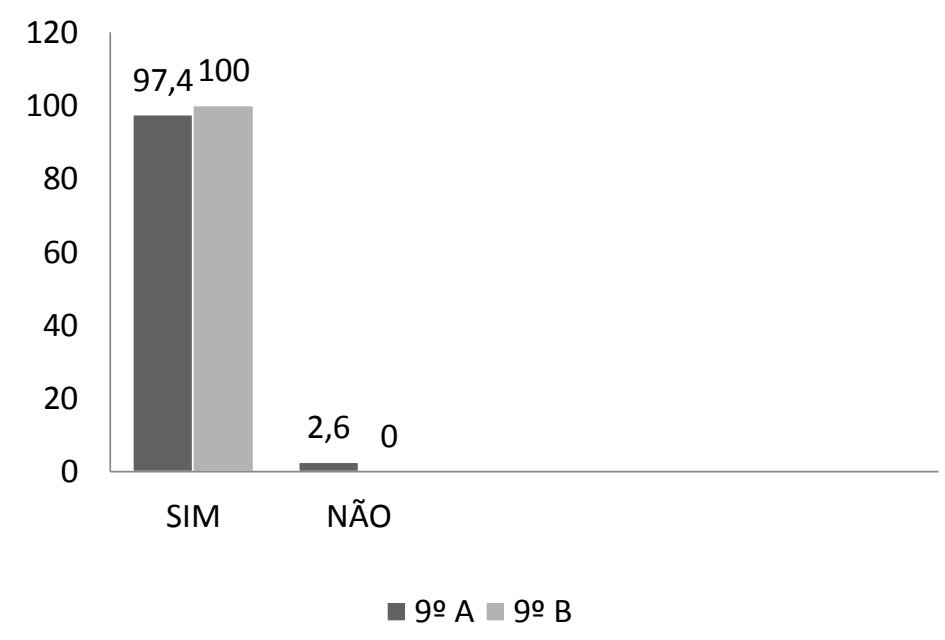

Gráfico 4. Porcentagem de importância da palestra realizada. (questão 07) Fonte: Dados da Pesquisa, 2017.

Com base nos dados aferidos nos gráficos acima, foi notória a importância da realização da palestra aos alunos, levando novos conhecimentos a cerca do cerrado para os mesmos, ampliando as suas percepções a cerca do tema.

Através do gráfico percebe-se que para ambas as turmas, o conhecimento pós palestra foi suficientemente bom, contribuindo para formação de uma cultura ecológica. Não deixando despercebido que boa parte dos alunos destacou como razoável seu conhecimento, alguns ruim e péssimo, destacando-se a importância da intensificação da educação ambiental no meio educacional. 


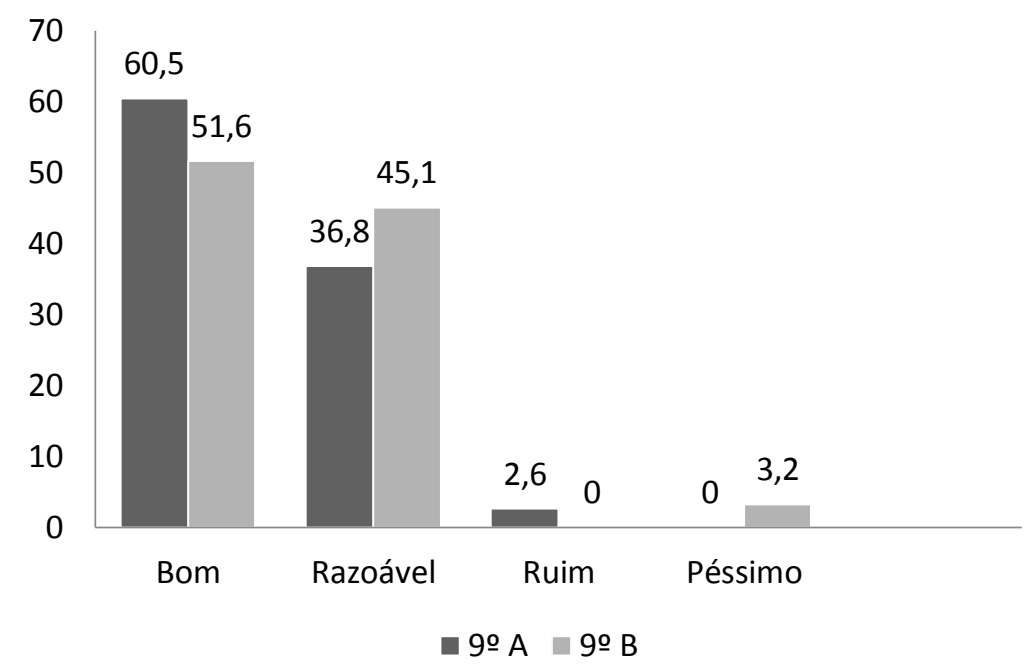

Gráfico 5. Porcentagem de conhecimento pós-palestra. (questão 08) Fonte: Dados da Pesquisa, 2017.

\section{Conclusão}

Pode-se perceber o quanto a influência da mídia está inserida no imaginário dos alunos, a capacidade que tem de influenciar seus conhecimentos e sua visão sobre o Cerrado, sendo muito importante que os professores tenham consciência do que a mídia apresenta sobre o bioma, para que possam dialogar em sala aula, diminuindo o grau de influência das mesmas sobre os alunos.

A ideia concebida que Cerrado é um bioma que possui pequena biodiversidade, escassez de água, pobreza nutricional do solo e secas por conta das queimadas que ocorrem na região, é o que mais caracteriza o bioma para a sociedade. No entanto, os resultados desta pesquisa não refletem todos os aspectos dessa ideia, uma vez que a biodiversidade foi bem descrita nas respostas dos alunos, contribuindo para a ideia de que a ação educacional pode refletir ações sociais no meio em que está sendo praticada.

Estes dados apontam para um conhecimento satisfatório e relevante sobre o cerrado e que este deve continuar sendo trabalhado tanto no Ensino Fundamental, como no Médio, a fim de garantir a ideia de preservação e sustentabilidade para as futuras gerações e para a manutenção do equilíbrio biológico entre os ecossistemas. Bem como a intensificação das práticas educacionais ambientais, a fim de formar cidadãos ecologicamente ativos no âmbito social. 
QUESTIONÁRIO DE AVALIAÇÃO, PRÉ-TESTE, SOBRE O TEMA CERRADO

Escola:

Série: Turma:

Data:

De acordo com seus conhecimentos sobre o Cerrado marque a resposta correta.

1. O Cerrado é:

( ) Uma formação ecológica brasileira;

( ) O resultado da ação humana sobre a mata atlântica;

( ) Um componente da floresta amazônica.

2. São características da flora do Cerrado:

( ) A predominância de cactos e arbustos;

( ) Árvores tortuosas, baixas, de casca grossa;

( ) Árvores altas e verdes o ano inteiro.

3. São exemplos da fauna do Cerrado:

( ) Onça-pintada; lobo-guará; tamanduá-bandeira; tucano; seriema; veadocampeiro;

( ) Siri; tartaruga-de-couro; baleia jubarte; água-viva; polvo; galo; mico-leãodourado;

( ) Vaca; cavalo; bezerro; carneiro; avestruz; búfalo; galinha; tucano; zebra; coelho;

4. O clima típico do Cerrado é caracterizado por:

( ) Período de chuva o ano inteiro, sem estação bem definida;

( ) Duas estações bem definidas, um período chuvoso no verão e um período de seca durante o inverno;

( ) As quatro estações do ano bem definidas, com temperaturas muito baixas no inverno podendo chegar a zero grau.

5. Qual a importância do fogo para o cerrado?

( ) Promover a quebra da dormência nas sementes e favorecer a floração de algumas plantas;

( ) Auxiliar no processo de preparação da terra para o plantio e consequentemente fornecer nutrientes ao solo;

( ) Promover o desmatamento de grandes áreas, facilitando o acesso da maquinaria agrícolas. 


\section{$4 \quad$ Referências}

BEZERRA R. G. SUESS, R. C. Abordagem do bioma cerrado em livros didáticos de biologia do ensino médio. Revista Holos, Rio Grande do Norte, v 1. p 233-242. 2013

BIZERRIL, M. X. A. O Cerrado e a escola: uma análise da educação ambiental no ensino fundamental do Distrito Federal. 2001. Tese de doutorado, Departamento de Ecologia, Universidade de Brasília, Brasília, 1990. 154f

COSTA, L. M.; OLSEVSKI, N. Caracterização da paisagem do Cerrado. In: FALEIRO, F. G. \& NETO, A. L. de F. (Eds). Savana: desafios e estratégias para o equilíbrio entre sociedade, agronegócio e recursos naturais. Planaltina (DF): Embrapa cerrado, 2008.

COUTINHO, L. M. As queimadas e seu papel biológico. Brasil Florestal, v.10, n.44, p 7-23. out./dez. 1980.

RIBEIRO, J. F.; WALTER, B. M. T. As principais fitofisionomias do bioma Cerrado. In: SANO S. M. ALMEIDA, S. P. (Eds.). Cerrado: ambiente e flora. Planaltina, DF: EMBRAPA-CPAC, 2008, v.2, p. 89-166

SOUZA, C.D.; FELFILI, J.M. Uso de plantas medicinais na região de Alto Paraíso de Goiás, GO, Brasil. Acta Botânica Brasileira, Goiás. v. 20, p. 135 - 142, 2006.

MMA - Ministério do Meio Ambiente. Plano de Ação para prevenção e controle do desmatamento e das queimadas: cerrado. Brasília: MMA, 200p., 2011.

MYERS, N. et al. Hotspots de biodiversidade para prioridades de conservação. Nature. v. 403, p. $853-858,2005$.

SILVA, C. d. S.; AGUIAR, O. R. B. F. A Teoria Behaviorista de Skinner. In: Psicologia da Aprendizagem. Teresina: UFPIUUAP, 2010. cap. 1, p-71.

XAVIER, R. P.; SOUZA, D. T. O que os pensam sobre o livro didático de inglês? Trabalhos em Linguística Aplicada, Campinas, v. 47, n. 1, p. 65-89, jan./jun. 2008.

VASCONCELLOS, H. S. R. A pesquisa - ação em projetos de Educação Ambiental. In: PEDRINI, A. G. (org). Educação Ambiental: Reflexões e práticas contemporâneas. Petrópolis: Vozes, 1997. 